\title{
Cord blood leptin levels in normal pregnancies, pregnancy induced hypertension and gestational diabetes mellitus
}

\author{
N Y Silva ${ }^{1}$, K H Tennekoon ${ }^{2}$, L Senanayake ${ }^{3}$ and E H Karunanayake ${ }^{1}$ \\ (Index words: cord blood leptin, neonatal anthropometry, fetal growth, placenta)
}

\begin{abstract}
Objective To compare cord blood leptin concentrations between normal pregnancy, pregnancy induced hypertension $(\mathrm{PIH})$, and gestational diabetes mellitus (GDM).

Design Cross-sectional study.

Setting Academic institutes and a tertiary care maternal hospital.

Method 48 newborns of normal pregnancies $(\mathrm{N}=18)$, pregnancy induced hypertension $(\mathrm{N}=16)$, and gestational diabetes mellitus $(\mathrm{N}=14)$ were studied. Cord blood samples were collected and newborn anthropometric indices recorded at delivery. Leptin concentrations were measured using an enzyme immunoassay.
\end{abstract}

Results Cord blood leptin levels were significantly different between the 3 groups (Kruskal-Wallis ANOVA; $\mathrm{P}=0.0064$ ), and the difference resulted mainly from higher levels in GDM than in $\mathrm{PIH}$ [geometric mean $(95 \% \mathrm{Cl})$ for GDM: $10.89(6.30,18.84)$ vs PIH: $3.49(2.14,5.69) \mathrm{ng} / \mathrm{ml}$ (Dunn's multiple comparison: $P<0.01$ ). This pattern persisted even when leptin levels were normalized to the ponderal index (Kruskal-Wallis ANOVA $P=0.0035$; Dunn's multiple comparison: $P<0.01)$. Leptin levels significantly and positively correlated with the ponderal index in normal pregnancy (Spearman $r=0.506, p<0.05$ ) and with birth weight in $\mathrm{PIH}(r=0.5463, p<0.05)$.

Conclusion In GDM cord blood leptin levels are significantly higher, and a source other than fetal adipocytes appears to contribute to this.

\section{Introduction}

Leptin, discovered in 1994, raised much optimism among biomedical researchers dedicated to devising a cure for obesity. It is secreted principally by white adipose tissue and regulates metabolic efficiency, energy expenditure and food intake [1]. Leptins' purported role as a metabolic signal in human reproduction was first identified in animal models and confirmed by extensive research in the clinical setting [2-6]. Secretion of leptin by other tissues, especially placental tissue, and its positive correlation with birth size indicated a role in the regulation of intrauterine growth [7-9].

Others observed similar levels when cord blood leptin was normalised to the fat content in appropriate, small and large for gestational age babies, indicating that cord blood leptin reflects adiposity rather than being a regulator of fetal growth [10]. This is further supported by normal birth weight seen in congenital leptin deficiency [11]. Fetal endocrine functions, including leptin secretion, are adversely affected by pregnancy complications. PIH and GDM cause microvascular changes in the placenta contributing to placental hypoxia [12-14]. Placental hypoxia is known to augment leptin secretion [15]. Insulin is also a potent stimulator of both adipocyte and placental leptin synthesis [16-18]. Lower cord blood levels and higher placental and maternal blood levels of leptin have been reported in pre-eclampsia associated with intrauterine growth retardation compared to normal pregnancies [10]. Umbilical cord blood and placental levels but not maternal blood levels of leptin are increased in GDM [10]. Leptin is also implicated in fetal programming leading to metabolic disorders in later adult life [19]. However, there are hardly any studies on cord blood leptin levels from south Asia, where prevalence of metabolic disorders is increasing.

\section{Materials and methods}

Forty-eight newborns were recruited from the Castle Street Hospital for Women, Colombo, for this study. The study received approval of the Institution Review Board and written informed consent was obtained from the mothers. All newborns were without any apparent congenital or hereditary disorder. Their mothers were 21 to 35 years of age and in para 1 and 2 . All the babies were born following singleton pregnancies at 36 to 40 weeks of gestation. Sixteen infants were delivered by women with $\mathrm{PIH}, 14$ by women with GDM and the remaining 18 by women with normal uncomplicated pregnancies.

$\mathrm{PIH}$ was diagnosed when maternal blood pressure rose to $140 / 90 \mathrm{~mm} \mathrm{Hg}$ or above for the first time after the

${ }^{1}$ Institute of Biochemistry, Molecular Biology and Biotechnology, ${ }^{2}$ Department of Physiology, Faculty of Medicine, University of Colombo, and ${ }^{3}$ Castle Street Hospital for Women, Colombo, Sri Lanka.

Correspondence: KHT, <khtennekoon@med.cmb.ac.lk>. Competing interests: none declared. Received 8 October 2007 and revised version accepted 28 February 2008. 
second trimester in the absence of proteinuria, with reversal of hypertension post-partum [20]. GDM was diagnosed when the 2-hour venous plasma glucose value was between $7.8 \mathrm{mmol} / \mathrm{l}(140 \mathrm{mg} / \mathrm{dl})$ and $11.1 \mathrm{mmol} / \mathrm{l}(200$ $\mathrm{mg} / \mathrm{dl})$ or exceeded $11.1 \mathrm{mmol} / \mathrm{l}(200 \mathrm{mg} / \mathrm{dl})$ during a standard $75 \mathrm{~g}$ oral glucose tolerance test at 24-28 weeks of gestation [21]. Women with normal pregnancy were those not having any acute or chronic medical problems or obstetric complications. Twenty babies were delivered by spontaneous or assisted vaginal delivery and 28 by caesarean section.

A mixed cord blood sample was collected at the time of delivery and birth weight recorded. Head circumference and length were recorded within 24 hours of birth using a standard tape and a Shorr infantometer respectively. Serum was separated and stored at $-20^{\circ} \mathrm{C}$. Leptin concentrations were measured using a commercially available enzyme immunoassay (EIA 2395, DRG International, Mountainside, NJ, USA) with a sensitivity of $1 \mathrm{ng} / \mathrm{mL}$. The assay was performed according to the manufacturer's recommendations.

Prism 2.01 software (GraphPad Prism, San Diego, California, USA) was used for statistical analysis. Leptin levels and newborn anthropometric indices between the three groups were compared using Kruskal-Wallis ANOVA with Dunn's post-test for multiple comparisons. Spearman's rank correlation test was used to identify correlations between leptin levels and anthropometric indices within each group.

\section{Results}

All the newborns were healthy. Their anthropometric indices are given in the table. Five in the PIH group and one each in the GDM and normal pregnancy groups had birth weights lower than $2500 \mathrm{~g}$, but birth weight and other anthropometric indices were not significantly different between the three groups.

Cord blood leptin levels (geometric mean and upper $95 \%$ confidence limit) in the three groups are shown in figure $1 \mathrm{~A}$. Cord blood leptin levels significantly differed between the 3 groups (Kruskal-Wallis ANOVA: $\mathrm{P}=0.0064$ ). This difference resulted from higher levels in GDM than in PIH [geometric mean (95\% CI) for GDM: 10.89 (6.30, 18.84) vs PIH: 3.49 (2.14, 5.69) ng/ml; Dunn's multiple comparison: $\mathrm{P}<0.01]$. Cord blood leptin levels normalized to the ponderal index are shown in figure $1 \mathrm{~B}$. The same pattern persisted, with higher levels in GDM than in PIH when leptin levels were normalized to the ponderal index (Kruskal-Wallis ANOVA P $=0.0035$; Dunn's multiple comparison: $\mathrm{P}<0.01)$. Though leptin levels before and after normalization to the ponderal index were lower in $\mathrm{PIH}$ and higher in GDM than in normal pregnancy, these differences were not statistically significant.

Cord blood leptin levels showed a significant positive correlation with the ponderal index in normal pregnancy (Spearman $\mathrm{r}=0.506, \mathrm{p}<0.05$ ), and with birth weight in $\mathrm{PIH}$ (Spearman $\mathrm{r}=0.5463, \mathrm{p}<0.05$ ). In GDM, cord blood leptin did not correlate with any of the neonatal anthropometric indices.

Table. Mean \pm SD of gestational age and anthropometric variables in the three groups

Normal ( $n=18$ ), PIH (pregnancy induced hypertension; $n=16$ ) and GDM (gestational diabetes mellitus; $n=14$ )

\begin{tabular}{llll}
\hline & $\begin{array}{l}\text { Normal } \\
(n=18)\end{array}$ & $\begin{array}{l}\text { PIH } \\
(n=16)\end{array}$ & $\begin{array}{l}\text { GDM } \\
(n=14)\end{array}$ \\
\hline Gestational age (weeks) & $39 \pm 2.23$ & $38 \pm 2.46$ & $38 \pm 1.12$ \\
Birth weight (kg) & $2.94 \pm 0.07$ & $2.78 \pm 0.12$ & $3.04 \pm 0.13$ \\
Birth length (m) & $0.52 \pm 0.05$ & $0.51 \pm 0.07$ & $0.511 \pm 0.09$ \\
Head circumference (m) & $0.33 \pm 0.036$ & $0.33 \pm 0.036$ & $0.34 \pm 0.05$ \\
Ponderal index (kg/m3) & $21.14 \pm 0.66$ & $20.65 \pm 0.93$ & $22.64 \pm 0.69$ \\
\hline
\end{tabular}


Leptin levels increase during pregnancy and return to pre-gravid levels after delivery [22]. The placenta is a major source of leptin in pregnant women. It has been estimated that about $95 \%$ of placental leptin enters the maternal circulation, and the remainder the fetal circulation [10]. Placental and adipocyte leptin synthesis is augmented by insulin $[10,16]$. Furthermore, placental leptin synthesis is increased in GDM [17]. We measured leptin levels in mixed cord blood, and thus the levels should reflect fetal as well as placental synthesis. However, leptin levels remained higher in GDM even when normalised for fetal adiposity. This suggests that increased placental synthesis is the most likely source of higher leptin levels, but confirmation was not possible as we did not directly measure placental leptin levels.

Recent studies suggest that cord blood leptin correlates strongly with the ponderal index rather than with the birth weight [10]. We observed a positive correlation between cord blood leptin concentrations and ponderal index only in normal pregnancies, whereas leptin levels correlated with birth weight in PIH. In our sample the majority of birth weights were within the normal range (table 1). However, the birth weight variation was greater in the PIH group than in the other two groups because the PIH group had the highest number of low birth weight babies. This may have resulted in the positive correlation seen between cord blood leptin and birth weight in PIH. Lack of correlation between cord blood leptin, and either the ponderal index or birth weight in GDM strengthens the view that a source other than fetal adipocytes contributes to higher leptin levels in GDM.

In conclusion, cord blood leptin concentrations in

Figure $1 \mathrm{~A}$ ). Cord blood leptin levels (geometric mean and upper $95 \%$ confidence limit) in the three groups. Normal pregnancy $(n=18)$, PIH (pregnancy induced hypertension; $n=16$ ) and GDM (gestational diabetes mellitus; $n=14)$.

Figure $1 \mathrm{~B}$ ). Cord blood leptin levels (geometric mean) normalised to ponderal index in the three groups Normal ( $n=18$ ), PIH (pregnancy induced hypertension; $n=16$ ) and GDM (gestational diabetes mellitus; $n=14$ ).

\section{Discussion}

We have shown that cord blood leptin levels are significantly elevated in GDM even when normalised for fetal adiposity. These findings are consistent with previous reports of higher cord blood leptin levels in infants born to diabetic mothers, and in large for gestational age (LGA) babies [18]. None of the newborns in our study, even those born to women with GDM, can be categorised as LGA. Our inability to observe a statistically significant difference in cord blood leptin levels between PIH and normal pregnancy or between GDM and normal pregnancy may have been due to small sample size.
GDM pregnancies are high and appear to be determined by factors other than birth size, the placenta being the most likely contributor.

\section{Acknowledgements}

We thank the Director and staff of Castle Street Hospital for Women and all the patients who volunteered to participate in this study. This work was supported by a SAREC Grant for Molecular Biology and Biotechnology.

\section{References}

1. Friedman JM, Halaas JL. Leptin and the regulation of body weight in mammals. Nature 1998; 395: 763-70.

2. Barash IA, Cheung CC, Weigle DS, Ren H, Kabigting EB, Kuijper JL, Clifton DK, Steiner RA. Leptin is a metabolic signal to the reproductive system. Endocrinology 1996; 137: 3144-7.

3. Chehab FF, Mounzih K, Lu R, Lim ME. Early onset of reproductive function in normal female mice treated with leptin. Science 1997; 275: 88-90.

4. Cunningham MJ, Clifton DK, Steiner RA. Leptin's action on the reproductive axis: perspectives and mechanisms. Biology of Reproduction 1999; 60: 216-22. 
5. Moschos S, Chan JL, Mantzoros CS. Leptin and reproduction: a review. Fertility and Sterility 2002; 77: 433-44.

6. Henson MC, Castracane VD. Leptin in pregnancy: an update. Biology of Reproduction 2006; 74: 218-29.

7. Koistinen HA, Koivisto VA, Anderson S, Karonen SL, Kontula K, Oksanen L, Teramo KA. Leptin concentrations in cord blood correlates with intrauterine growth. Journal of Clinical Endocrinology and Metabolism 1997; 82: 328-30.

8. Ong KKL, Ahmed ML, Sherriff A, Woods KA, Watts A, Golding J. Cord leptin is associated with size at birth and predicts infancy weight gain in humans. Journal of Clinical Endocrinology and Metabolism 1999; 84: 1145-8.

9. Matsuda J, Yokoto I, Ilda M, Murakami T, Naito E, Ito M, Shima K, Kuroda Y. Serum leptin concentration in cord blood: relationship to birth weight and gender. Journal of Clinical Endocrinology and Metabolism 1997; 82: 1642-4.

10. Mouzon SH, Lepercq J, Catalano P. The known and unknown of leptin in pregnancy. American Journal of Obstetrics and Gynecology 2006; 194: 1537-45.

11. Strobel A, Camoin TIL, Ozata M, Strosberg AD. A leptin missense mutation associated with hypogonadism and morbid obesity. Nature Genetics 1998; 18: 213-5.

12. Lain KY, Roberts JM. Contemporary concepts of the pathogenesis and management of preeclampsia. Journal of American Medical Association 2002; 287: 3183-6.

13. Jirkovska M, Kubinova L, Janacek J, Moravcova M, Krejci V, Karen P. Topological properties and spatial organization of villous capillaries in normal and diabetic placentas. Journal of Vascular Research 2002; 39: 268-78.

14. Soleymanlou N, Jurisica I, Nevo O, Ietta F, Zhang X, Zamudio S, Post M, Caniggia I. Molecular evidence of placental hypoxia in preeclampsia. Journal of Clinical Endocrinology and Metabolism 2005; 90: 4299-308.
15. Mise H, Sagawa N, Matsumoto T, Yura S, Nanno H, Itoh H, Mori T, Masuzaki H, Hosoda K, Ogawa Y, Nakao K. Augmented placental production of leptin in preeclampsia: possible involvement of placental hypoxia. Journal of Clinical Endocrinology and Metabolism 1998; 83: 3225-9.

16. Wabitsch M, Jensen PB, Blum WF, Christoffersen CT, Englaro P, Heinze E, Rascher W, Teller W, Tornqvist H, Hauner H. Insulin and cortisol promote leptin production in cultured human fat cells. Diabetes 1999; 45: 1435-38.

17. Lepercq J, Cauzac M, Lahlou N, Timsit J, Girard J, Auwerx J, Mouzon SH. Overexpression of placental leptin in diabetic pregnancy: a critical role for insulin. Diabetes 1998; 47: 847-50.

18. Shekawat PS, Garland JS, Shivpuri C, Mick GJ, Sasidharan P, Pelz CJ, McCormick KL. Neonatal cord blood leptin: its relationship to birth weight, body mass index, maternal diabetes and steroids. Paediatric Research 1998; 43: 338-43.

19. McMillen IC, Edwards LJ, Duffield J, Muhlhausler BS. Regulation of leptin synthesis and secretion before birth: implications for the early programming of adult obesity. Reproduction 2006; 131: 415-27.

20. Roberts JM, Pearson G, Cutler J, Lindheimer M. Summary of the NHLBI working group on research on hypertension during pregnancy. Hypertension 2003; 41: 437-45.

21. World Health Organization. Definition, diagnosis and classification of diabetes mellitus. Report of a WHO consultation, Geneva, Switzerland, WHO/NCD/NCS/99.2, 1999.

22. Sivan E, Whittaker PG, Sinha D, Homko CJ, Lin M, Reece EA, Boden G. Leptin in human pregnancy: the relationship with gestational hormones. American Journal of Obstetrics and Gynecology 1998; 179: 1128-32.

\section{On his blindness}

When I consider how my light is spent,

Ere half my days, in this dark world and wide,

And that one talent which is death to hide

Lodged with me useless, though my soul more bent

To serve therewith my Maker, and present

My true account, lest he returning chide,

'Doth God exact day-labour, light denied?'

I fondly ask. But Patience, to prevent

That murmur, soon replies: 'God doth not need

Either man's work or his own gifts; who best

Bear his mild yoke, they serve him best. His state

Is kingly: thousand at his bidding speed,

And post o'er land and ocean without rest;

They also serve who only stand and wait.'

John Milton. English poet. (1608 - 1674) 